\title{
Heterogeneous acidic catalysts for the tetrahydropyranylation of alcohols and phenols in green ethereal solvents
}

\author{
Ugo Azzena*, Massimo Carraro, Gloria Modugno, Luisa Pisano and Luigi Urtis
}

\author{
Letter \\ Address: \\ Dipartimento di Chimica e Farmacia, Università degli Studi di Sassari, \\ via Vienna 2, 07100 - Sassari, Italy \\ Email: \\ Ugo Azzena* - ugo@uniss.it \\ * Corresponding author \\ Keywords: \\ green chemistry; green solvents; heterogeneous catalysts; multistep \\ reactions; tetrahydropyranylation
}

\author{
Beilstein J. Org. Chem. 2018, 14, 1655-1659. \\ doi:10.3762/bjoc. 14.141 \\ Received: 30 April 2018 \\ Accepted: 19 June 2018 \\ Published: 03 July 2018 \\ Associate Editor: L. Vaccaro \\ (c) 2018 Azzena et al.; licensee Beilstein-Institut. \\ License and terms: see end of document.
}

\begin{abstract}
The application of heterogeneous catalysis and green solvents to the set up of widely employed reactions is a challenge in contemporary organic chemistry. We applied such an approach to the synthesis and further conversion of tetrahydropyranyl ethers, an important class of compounds widely employed in multistep syntheses. Several alcohols and phenols were almost quantitatively converted into the corresponding tetrahydropyranyl ethers in cyclopentyl methyl ether or 2-methyltetrahydrofuran employing $\mathrm{NH}_{4} \mathrm{HSO}_{4}$ supported on $\mathrm{SiO}_{2}$ as a recyclable acidic catalyst. Easy work up of the reaction mixtures and the versatility of the solvents allowed further conversion of the reaction products under one-pot reaction conditions.
\end{abstract}

\section{Introduction}

Due to their general stability to a wide range of reagents and ease of removal, tetrahydropyranyl (THP) ethers are widely employed in multistep organic synthesis for the protection of hydroxy derivatives $[1,2]$. In addition, they can be converted into a wealth of useful functional groups [2,3], and found employment as fragrances or pro-fragrances in everyday life [4-7]. Although a lot of work has been devoted to the search of low impact, heterogeneous and recyclable catalysts to promote THP ethers synthesis [2,8-14], to the best of our knowledge no attention was dedicated to their employment in low impact solvents.

From this point of view, it is worth noting that although ethers are the solvents of choice for reactions involving highly polar nucleophilic reagents such as organolithium and organomagnesium compounds or aluminium hydrides, tetrahydropyranylation reactions are usually run in hydrocarbons, chloroalkanes or dipolar aprotic solvents [1,2,8-15], thus affording a paradig- 
matic example of the ironic Murphy's Law of Solvents, recently stated by Jessop et al. [16]: "The best solvent for any process step is bad for the next step".

Starting from these premises and following our interest in the development of reaction procedures in low impact solvents $[17,18]$, we report here on the tetrahydropyranylation of alcohols and phenols in cyclopentyl methyl ether (CPME) and 2-methyltetrahydrofuran (2-MeTHF) in the presence of heterogeneous acidic catalysts. Indeed, both CPME [19-22] and 2-MeTHF [21-25] are characterized by relatively high boiling points, a narrow explosion range, hydrophobicity, easy drying and recovery possibilities. Additionally, CPME is produced via a $100 \%$ atom economical reaction $[19,20]$, whilst $2-\mathrm{MeTHF}$ is accessible from renewable resources [21,23]. Finally, it is worth noting that besides being moderately irritant, both solvents are characterized by low toxicities and are considered negative for genotoxicity and mutagenicity [26-28]. Due to these environmentally friendly characteristics, CPME and 2-MeTHF appear as versatile green alternatives to ethereal solvents such as tetrahydrofuran, dioxane, diethyl ether or methyl tert-butyl ether.

Aiming to the development of a particularly practical and environmentally friendly procedure to the generation of THP ethers, we devoted our efforts to the employment of heterogeneous acidic catalysts $[29,30]$ in order to set up conditions allowing easy processing of the reaction mixtures and, possibly, the recovery and recycling of the catalyst.

\section{Results and Discussion}

Taking 2-phenylethanol (1a) as a model compound, we investigated its conversion into the corresponding THP ether 3a by reacting $4 \mathrm{M}$ solutions of this alcohol with a slight excess (1.1 equiv) of 3,4-dihydro-2 $H$-pyran (2, DHP) in the presence of several acidic heterogeneous catalysts (Scheme 1 and Table 1). The recovered reaction mixtures were very simply elaborated by filtering the catalyst followed by evaporation of the solvent in vacuo.

\footnotetext{
$\underset{\mathbf{1 a}}{\mathrm{PhCH}_{2} \mathrm{CH}_{2}-\mathrm{OH}+\overbrace{\mathbf{2}} \frac{\text { catalyst }}{\underset{\text { solvent, rt }}{2}}} \underset{\mathbf{3 a}}{\mathrm{PhCH}_{2} \mathrm{CH}_{2}-\mathrm{OTHP}}$

Scheme 1: Synthesis of THP ether 3a.
}

No reaction occurred in both solvents in the absence of an acidic catalyst as well as in the presence of several ammonium salts, i.e., $\mathrm{NH}_{4} \mathrm{Cl}, \mathrm{NH}_{4} \mathrm{Br}$ and $\mathrm{NH}_{4} \mathrm{H}_{2} \mathrm{PO}_{4}$ (Table 1, entries 1-4). On the other hand, inorganic salts with a relatively higher acidity, i.e., $\mathrm{NH}_{4} \mathrm{HSO}_{4}, \mathrm{NaHSO}_{4}$ and $\mathrm{KHSO}_{4}$ [31], as well as Amberlyst 15 and Montmorillonite K10, efficiently promoted practically quantitative conversion of the starting material into the corresponding tetrahydropyranyl ether 3a within a few hours in both solvents (Table 1, entries 5-9).

Good results were also obtained with a $25 \mathrm{wt} \%$ dispersion of $\mathrm{NH}_{4} \mathrm{HSO}_{4}$ over $\mathrm{SiO}_{2}\left(\mathrm{NH}_{4} \mathrm{HSO}_{4} @ \mathrm{SiO}_{2}\right.$, Table 1, entries 10 and 11). Additionally, the supported catalyst, which can be stored in a desiccator for several months with no detrimental effects, is particularly easy to recover and was recycled up to 4 times with no evident loss of activity (Table 1, entry 10). Its robustness was further assessed by the good qualitative matching between the IR spectra of the fresh and recycled cata-

\begin{tabular}{|c|c|c|c|}
\hline entry & solvent & catalyst (\%) & $3 a / 1 a(\%)^{b}$ \\
\hline 1 & CPME or 2-MeTHF & none & $<5:>95$ \\
\hline 2 & CPME or 2-MeTHF & $\mathrm{NH}_{4} \mathrm{Cl}$ & $<5:>95$ \\
\hline 3 & CPME or 2-MeTHF & $\mathrm{NH}_{4} \mathrm{Br}$ & $<5:>95$ \\
\hline 4 & CPME or 2-MeTHF & $\mathrm{NH}_{4} \mathrm{H}_{2} \mathrm{PO}_{4}$ & $<5:>95$ \\
\hline 5 & CPME or 2-MeTHF & $\mathrm{NH}_{4} \mathrm{HSO}_{4}$ & $94: 6$ \\
\hline 6 & CPME & $\mathrm{NaHSO}_{4}$ & $93: 7$ \\
\hline 7 & CPME & $\mathrm{KHSO}_{4}$ & $93: 7$ \\
\hline 8 & 2-MeTHF & Amberlyst 15 & $>95:<5$ \\
\hline 9 & CPME or 2-MeTHF & Montmorillonite $\mathrm{K} 10^{\mathrm{C}}$ & $>95:<5$ \\
\hline 10 & CPME & $\mathrm{NH}_{4} \mathrm{HSO}_{4} @ \mathrm{SiO}_{2}^{\mathrm{d}, \mathrm{e}}$ & $>95:<5$ \\
\hline 11 & 2-MeTHF & $\mathrm{NH}_{4} \mathrm{HSO}_{4} @ \mathrm{SiO}_{2}$ & $>95:<5$ \\
\hline 12 & CPME & $\mathrm{NH}_{4} \mathrm{HSO}_{4} @ \mathrm{SiO}_{2}^{\mathrm{f}}$ & $93: 7$ \\
\hline
\end{tabular}

${ }^{a}$ All reactions were run at rt during $4 \mathrm{~h}$ in the presence of the catalyst ( $3 \mathrm{~mol} \%$ of $1 \mathrm{a}$, unless otherwise indicated). ${ }^{\mathrm{b}} \mathrm{As}$ determined by ${ }^{1} \mathrm{H} \mathrm{NMR}$ analyses of crude reaction mixtures; no other product was detected besides $\mathbf{1 a}$. ${ }^{\mathrm{c}} \mathbf{1 a} /$ catalyst $=3 \mathrm{wt} \%$. ${ }^{\mathrm{d}}$ Comparable results were obtained after

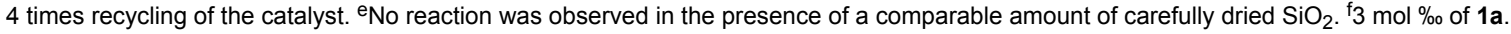


lysts (see Supporting Information File 1, Figure S1). Additionally, it is worth noting that a comparable result was obtained by reducing the amount of catalyst to one tenth ( $3 \mathrm{~mol} \%$ of $\mathbf{1 a}$, Table 1, entry 12).

Finally, both CPME and 2-MeTHF proved stable towards such an acidic supported catalyst, as established by the absence of any decomposition product within the reaction mixtures, as determined by ${ }^{1} \mathrm{H},{ }^{13} \mathrm{C}$ NMR and gas-liquid chromatography analyses [32].

Due to the ease of the preparation from particularly cheap starting materials, the ease of handling and its high activity, we further investigated the ability of $\mathrm{NH}_{4} \mathrm{HSO}_{4} @ \mathrm{SiO}_{2}$ to catalyze the synthesis of different THP ethers in low impact ethereal solvents. Accordingly, the reactions were performed in the presence of $3 \mathrm{~mol} \%$ of the catalyst and were successfully applied to the synthesis of a series of THP ethers of functionalized and non-functionalized alcohols and phenols, including some known fragrances $(\mathbf{3 g}-\mathbf{j}$ and $\mathbf{3 1})$ [4-7], as illustrated in Scheme 2.

Conversions exceeding 95\% were achieved under the mild conditions illustrated in Scheme 2 with primary aliphatic and benzylic alcohols $\mathbf{1 b}-\mathbf{h}$. A notable exception is the low conversion of 4-bromobenzyl alcohol 1e in CMPE, most probably due to the low solubility of the starting material in this solvent. This disadvantage was easily overcome by performing the reaction in 2-MeTHF.

More demanding conditions (2.0 equiv of 2 ) were required to obtain good conversions of a secondary alcohol, i.e, $(1 R, 2 S, 5 R)$ 2-isopropyl-5-methylcyclohexanol ((-)-menthol, 1i). The reaction afforded an almost 1:1 mixture of only two diastereoiso-

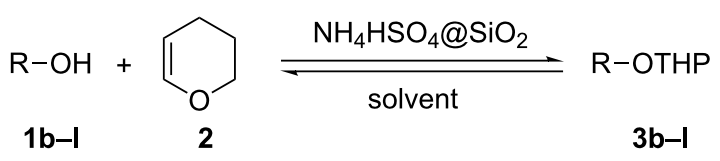

$$
\widehat{\mathrm{Cl}} \mathrm{Y}_{4} \mathrm{OTHP}
$$

3b, $>95 \%(87 \%)$

2-MeTHF or CPME<smiles>P[OH+]Cc1ccc(Br)cc1</smiles>

3e, $>95 \%$ (91\%), 2-MeTHF $50 \%$, CPME $^{\mathrm{b}}$<smiles>CCCC(CC)C[OH+]F</smiles>

$3 h,{ }^{c}>95 \%(92 \%), 2-M e T H F$<smiles></smiles>

3c, $>95 \%(91 \%), 2-$ MeTHF $^{a}$<smiles>COC(=O)c1ccc(C[OH+])cc1</smiles>

3f, $>95 \%(89 \%)$ 2-MeTHF or CPME<smiles>CC(C)[C@H]1CC[C@@H](C)C[C@H]1[OH+]</smiles>

$3 \mathbf{i}^{\mathrm{c}}{ }^{86 \%}, 2$-MeTHF $>95 \%(92 \%), 2.0$ equiv DHP, 2-MeTHF or CPME<smiles>F[OH+]Cc1ccc(Cl)cc1</smiles>

3d, >95\% (92\%), 2-MeTHF<smiles>COc1ccc(C[OH+]F)cc1</smiles>

$3 \mathbf{g},>95 \%(90 \%)$ 2-MeTHF or CPME<smiles>C=CC(C)(CCC=C(C)C)[OH+]P</smiles>

3j, ${ }^{\mathrm{C}} 80 \%, 2$ equiv DHP, $8 \mathrm{~h}, \mathrm{rt}, 2-\mathrm{MeTHF}$ $84 \%, 2$ equiv DHP, $8 \mathrm{~h}, \mathrm{rt}, \mathrm{CPME}$ $93 \%(85 \%)$, 2 equiv DHP, $8 \mathrm{~h}, 40^{\circ} \mathrm{C}, \mathrm{CPME}$<smiles>CC(=O)CCc1ccc([OH+]F)cc1</smiles>

3k, 79\%, 2-MeTHF; 68\%,CPME $92 \%(89 \%), 18 \mathrm{~h}, 50{ }^{\circ} \mathrm{C}, 2-\mathrm{MeTHF}$

\section{I, 81\%, 2-MeTHF; 76\%, CPME \\ $91 \%(84 \%), 2.0$ equiv DHP, \\ $18 \mathrm{~h}, 50{ }^{\circ} \mathrm{C}, 2-\mathrm{MeTHF}$}

Scheme 2: Synthesis of THP ethers 3b-I in the presence of $\mathrm{NH}_{4} \mathrm{HSO}_{4} @ \mathrm{SiO}_{2}$. All reactions were run at rt, in the presence of 1.1 equiv of 2 and $3 \mathrm{~mol} \%$ of catalyst during $4 \mathrm{~h}$, unless otherwise indicated; percentages represent conversion of the starting materials as determined by ${ }^{1} \mathrm{H}$ NMR;

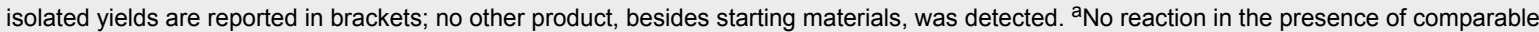
amounts of $\mathrm{NH}_{4} \mathrm{Br}$ or $\mathrm{SiO}_{2}$. ${ }^{\mathrm{b}} 1 \mathrm{e}$ is almost insoluble in CPME. ${ }^{\mathrm{c}} 1: 1$ mixture of diastereoisomers. 
mers as determined by ${ }^{1} \mathrm{H}$ and ${ }^{13} \mathrm{C}$ NMR analysis of the crude reaction mixture, thus suggesting that it occurs with no epimerization at $\mathrm{C} 1$.

This result was confirmed by submitting compound $\mathbf{3 i}$ to acidcatalyzed deprotection with $\mathrm{H}_{2} \mathrm{SO}_{4} @ \mathrm{SiO}_{2}$ (25 wt \% [33] as depicted in Scheme 3). Alcohol 1i, was recovered as a single stereoisomer, identical to the commercially available starting material, as determined by ${ }^{1} \mathrm{H}$ and ${ }^{13} \mathrm{C} \mathrm{NMR}$ analysis of the crude reaction mixture (see Supporting Information File 1).

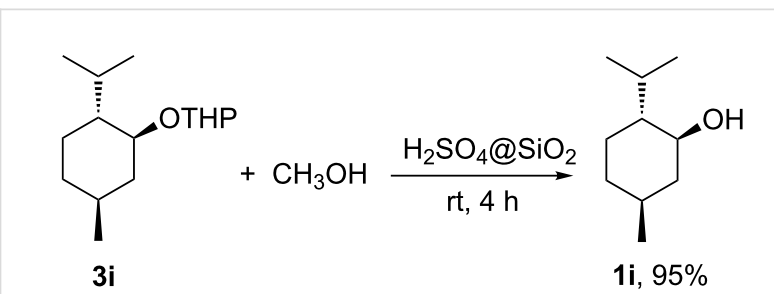

Scheme 3: Deprotection of THP ether 3i.

Finally, the tetrahydropyranylation of a tertiary alcohol $\mathbf{1} \mathbf{j}$ as well as of phenols $\mathbf{1 k}$ and $\mathbf{1 l}$ required, besides the employment of 2.0 equiv of DHP, relatively longer reaction times and higher temperatures. It is worth noting that under our mild reaction conditions we did not observe any isomerisation of the acidsensitive allylic alcohol $\mathbf{1 j}$ [34].

To stress the usefulness of a tetrahydropyranylation reaction performed in a green ethereal solvent and in the presence of a heterogeneous acidic catalyst, we realized two one-pot procedures employing either 2-MeTHF or CPME as a solvent.

Accordingly, the mixture obtained by reacting $\mathbf{1 f}$ with 1.1 equiv of 2 and 3 mol \%o of $\mathrm{NH}_{4} \mathrm{HSO}_{4} @ \mathrm{SiO}_{2}$ in 2-MeTHF under dry
Ar was filtered and dropwise added to a vigorously stirred freshly prepared solution of $\mathrm{EtMgBr}$ in the same solvent at $\mathrm{rt}$. Aqueous work-up and flash chromatography afforded the desired tertiary alcohol $\mathbf{4 f a}$ in $78 \%$ yield (Scheme 4 ).

Under similar conditions, protection of $\mathbf{1 f}$ in CPME, followed by filtration and dropwise addition of the resulting solution to a suspension of $\mathrm{LiAlH}_{4}$ in the same solvent, afforded the monoprotected diol $\mathbf{4 f b}$ in almost quantitative yield (Scheme 5).

\section{Conclusion}

The above reported results show that several heterogeneous acidic catalysts efficiently promote the tetrahydropyranylation of an alcoholic model compound in low impact ethereal solvents under mild conditions. Further investigations show that $\mathrm{NH}_{4} \mathrm{HSO}_{4} @ \mathrm{SiO}_{2}$, easily prepared from inexpensive starting materials, successfully catalyzes the protection of a variety of functionalized and non-functionalized alcohols and phenols, including an optically pure alcohol with no detrimental effects on its stereochemistry. Due to a particularly simple work-up procedure, $\mathrm{NH}_{4} \mathrm{HSO}_{4} @ \mathrm{SiO}_{2}$ can be easily recovered and recycled several times. The easy removal of the acidic catalyst from the reaction mixtures and the versatility of the employed solvents allowed the successful further conversion of the reaction products with strong nucleophiles under one-pot conditions.

\section{Supporting Information}

\section{Supporting Information File 1}

Full experimental details, copies of IR spectra of fresh and recycled $\mathrm{NH}_{4} \mathrm{HSO}_{4} @ \mathrm{SiO}_{2}$ and copies of ${ }^{1} \mathrm{H}$ and ${ }^{13} \mathrm{C} \mathrm{NMR}$ spectra.

[https://www.beilstein-journals.org/bjoc/content/ supplementary/1860-5397-14-141-S1.pdf]

\footnotetext{
Scheme 4: One-pot synthesis of 3-[4-(tetrahydro-2H-pyran-2-yl)oxymethylphenyl]-3-pentanol (4fa).
}

Scheme 5: One-pot synthesis of 4-(tetrahydro-2H-pyran-2-yloxymethyl)benzyl alcohol (4fb).




\section{ORCID ${ }^{\circledR}$ iDs}

Ugo Azzena - https://orcid.org/0000-0002-7154-7308 Massimo Carraro - https://orcid.org/0000-0003-2712-6132 Luisa Pisano - https://orcid.org/0000-0003-2782-5400 Luigi Urtis - https://orcid.org/0000-0002-6804-7185

\section{References}

1. Green, T. W.; Wuts, P. G. M. Protective Groups in Organic Synthesis, 3rd ed.; Wiley-VCH: New York, 1999; pp 49-54.

2. Kumar, B.; Aga, M. A.; Rouf, A.; Shah, B. A.; Taneja, S. C. RSC Adv. 2014, 4, 21121-21130. doi:10.1039/c4ra02093f

3. Bergueiro, J.; Montenegro, J.; Saá, C.; López, S. RSC Adv. 2014, 4, 14475-14479. doi:10.1039/c4ra00655k

4. Hermann,, A. Profragrances and Properfumes. In The Chemistry and Biology of Volatiles; Hermann, A., Ed.; Wiley: Chichester, 2010; pp 333-362.

5. Anselmi, C.; Centini, M.; Mariani, M.; Sega, A.; Pelosi, P. J. Agric. Food Chem. 1992, 40, 853-856. doi:10.1021/jf00017a030

6. Sivik, M. R. Profragrance cyclic acetals. WO Patent WO 99/00377, Jan 7, 1999.

7. Lamberti, V.; Winnegrad, R. R. Detergent Composition Containing the Ethers and Esters of Tetrahydrofuran and Tetrahydropyran. U.S. Patent US3668134, June 6, 1972.

8. Jeppesen, A.; Nielsen, B. E.; Larsen, D.; Akselsen, O. M.; Sølling, T. I.; Brock-Nannestad, T.; Pittelkow, M. Org. Biomol. Chem. 2017, 15, 2784-2790. doi:10.1039/c7ob00441a

9. Crites, C.-O. L.; Lima, F. M.; Marin, M. L.; Netto-Ferreira, J. C.; Impellizzeri, S.; Hallett-Tapley, G. L.; Scaiano, J. C. Can. J. Chem. 2016, 94, 712-714. doi:10.1139/cjc-2015-0538

10. Shin, H. S.; Opanasenko, M.; Cabello, C. P.; Ryoo, R.; Čejka, J. Appl. Catal., A 2017, 537, 24-32. doi:10.1016/j.apcata.2017.02.019

11. Yadegari, M.; Moghadam, M. Appl. Organomet. Chem. 2016, 30 , 872-875. doi:10.1002/aoc.3515

12. Azizi, N.; Abdoli-Senejani, M.; Abbasi, F. Tetrahedron Lett. 2016, 57, 5009-5011. doi:10.1016/j.tetlet.2016.09.099

13. Sartori, G.; Maggi, R. Chem. Rev. 2010, 110, PR1-PR54. doi:10.1021/cr900316t and references therein.

14. Williams, D. B. G.; Simelane, S. B.; Lawton, M.; Kinfe, H. H. Tetrahedron 2010, 66, 4573-4576. doi:10.1016/j.tet.2010.04.053

15. Moghadam, M.; Tangestaninejad, S.; Mirkhani, V.; Mohammadpoor-Baltork, I.; Gharaati, S. J. Mol. Catal. A: Chem. 2011, 337, 95-101. doi:10.1016/j.molcata.2011.01.023

16. Jessop, P. G. Green Chem. 2016, 18, 2577-2578. doi:10.1039/c6gc90039a

17. Azzena, U.; Kondrot, F.; Pisano, L.; Pittalis, M. Appl. Organomet. Chem. 2012, 26, 180-184. doi:10.1002/aoc.2834

18. Azzena, U.; Carraro, M.; Mamuye, A. D.; Murgia, I.; Pisano, L.; Zedde, G. Green Chem. 2015, 17, 3281-3284. doi:10.1039/c5gc00465a

19. Watanabe, K.; Yamagiwa, N.; Torisawa, Y. Org. Process Res. Dev. 2007, 11, 251-258. doi:10.1021/op0680136

20. Sakamoto, S. Chim. Oggi 2013, 31, 24-27.

21. Calvo-Flores, F. G.; Monteagudo-Arrebola, M. J.; Dobado, J. A.; Isac-García, J. Top. Curr. Chem. 2018, 376, 18. doi:10.1007/s41061-018-0191-6
22. Scott, J. L.; Sneddon, H. F. Green Solvents. In Green Techniques for Organic Synthesis and Medicinal Chemistry, 2nd ed.; Zhang, W.; Cue, B. W., Eds.; Wiley-VCH: Weinheim, 2018; pp 21-42. doi:10.1002/9781119288152.ch2

23. Aycock, D. F. Org. Process Res. Dev. 2007, 11, 156-159. doi:10.1021/op060155c and references therein.

24. Pace, V.; Hoyos, P.; Castoldi, L.; Domínguez de María, P.; Alcántara, A. R. ChemSusChem 2012, 5, 1369-1379. doi:10.1002/cssc.201100780 and references therein.

25. Clarke, C. J.; Tu, W.-C.; Levers, O.; Bröhl, A.; Hallett, J. P. Chem. Rev. 2018, 118, 747-800. doi:10.1021/acs.chemrev.7b00571

26. Watanabe, K. Molecules 2013, 18, 3183-3194. doi:10.3390/molecules18033183

27. Antonucci, V.; Coleman, J.; Ferry, J. B.; Johnson, N.; Mathe, M.; Scott, J. P.; Xu, J. Org. Process Res. Dev. 2011, 15, 939-941. doi:10.1021/op100303c

28. Parris, P.; Duncan, J. N.; Fleetwood, A.; Beierschmitt, W. P. Regul. Toxicol. Pharmacol. 2017, 87, 54-63. doi:10.1016/j.yrtph.2017.04.012

29. Gupta, P.; Paul, S. Catal. Today 2014, 236, 153-170. doi:10.1016/j.cattod.2014.04.010

30. Kaur, M.; Sharma, S.; Bedi, P. M. S. Chin. J. Catal. 2015, 36, 520-549. doi:10.1016/S1872-2067(14)60299-0

31. $\mathrm{pKa}$ (in $\mathrm{H}_{2} \mathrm{O}$ ): $\mathrm{NH}_{4}{ }^{+}=9.25, \mathrm{H}_{2} \mathrm{PO}_{4}^{-}=7.198$, and $\mathrm{HSO}_{4}{ }^{-}=1.99$. Dean, J. A. Lange's Handbook of Chemistry, McGraw-Hill: New York, 15th edn., 1999, Table 8.7

32. As a note of caution it is worth noting that reactions run in 2-MeTHF under more demanding conditions $\left(40^{\circ} \mathrm{C}, 8 \mathrm{~h}\right)$, led to the formation of minor amounts of peroxides ( $<5 \mathrm{mg} / \mathrm{L}$ ) as semiquantitatively evaluated with a commercially available kit (Quantofix ${ }^{\circledR}$, measuring range 0.5-25 mg $\cdot \mathrm{L}^{-1} \mathrm{H}_{2} \mathrm{O}_{2}$ ). Accordingly, such reactions were safely run under an inert atmosphere.

33. Reaction of $3 \mathbf{i}$ with $\mathrm{CH}_{3} \mathrm{OH}$ in the presence of $3 \mathrm{~mol} \%$ of $\mathrm{NH}_{4} \mathrm{HSO}_{4} @ \mathrm{SiO}_{2}$ during $12 \mathrm{~h}$ led to a relatively low conversion of the starting material $(\mathbf{3} \mathbf{i} / \mathbf{1} \mathbf{i}=55: 45)$.

34. Miyashita, M.; Yoshikoshi, A.; Grieco, P. A. J. Org. Chem. 1977, 42, 3772-3774. doi:10.1021/jo00443a038

\section{License and Terms}

This is an Open Access article under the terms of the Creative Commons Attribution License (http://creativecommons.org/licenses/by/4.0), which permits unrestricted use, distribution, and reproduction in any medium, provided the original work is properly cited.

The license is subject to the Beilstein Journal of Organic Chemistry terms and conditions: (https://www.beilstein-journals.org/bjoc)

The definitive version of this article is the electronic one which can be found at: doi:10.3762/bjoc. 14.141 